\title{
Behaviour of adult sea trout Salmo trutta that survive or die at sea
}

Kristensen, Martin Lykke; Righton, David; Villar-Guerra, Diego del; Baktoft, Henrik; Aarestrup, Kim

Published in:

Estuarine, Coastal and Shelf Science

Link to article, DOI:

10.1016/j.ecss.2019.106310

Publication date:

2019

Document Version

Peer reviewed version

Link back to DTU Orbit

Citation (APA):

Kristensen, M. L., Righton, D., Villar-Guerra, D. D., Baktoft, H., \& Aarestrup, K. (2019). Behaviour of adult sea trout Salmo trutta that survive or die at sea. Estuarine, Coastal and Shelf Science, 227, [106310]. https://doi.org/10.1016/j.ecss.2019.106310

\section{General rights}

Copyright and moral rights for the publications made accessible in the public portal are retained by the authors and/or other copyright owners and it is a condition of accessing publications that users recognise and abide by the legal requirements associated with these rights.

- Users may download and print one copy of any publication from the public portal for the purpose of private study or research.

- You may not further distribute the material or use it for any profit-making activity or commercial gain

- You may freely distribute the URL identifying the publication in the public portal 
Title:

2 Behaviour of adult sea trout Salmo trutta that survive or die at sea

\section{Authors:}

$4 \quad{ }^{1}$ Martin L. Kristensen, ${ }^{2}$ David Righton, ${ }^{3}$ Diego del Villar-Guerra, ${ }^{1}$ Henrik Baktoft $\&{ }^{1}$ Kim Aarestrup

\section{Affiliations:}

$7 \quad{ }^{1}$ Technical University of Denmark, National Institute for Aquatic Resources, 8600 Silkeborg, Denmark

$8 \quad{ }^{2}$ Centre for Environment, Fisheries and Aquaculture Sciences, Lowestoft NR33 OHT, United Kingdom

$9 \quad{ }^{3}$ Ness \& Beauly Fisheries Trust, Inverness-Shire IV4 7BE, United Kingdom

10

11

Author for correspondence:

12 Martin Lykke Kristensen: makri@aqua.dtu.dk ,+45 40987793. 


\section{(} 4 6 7

\section{Abstract}

We tagged 125 sea trout kelts $(460-925 \mathrm{~mm})$ in seven Danish rivers with positively buoyant DSTs. Fiftythree (42\%) tags were recovered, enabling a comparison of behaviour in kelts that survived the marine period and kelts that did not. Data revealed an estimated mean survival time at sea of 14.3 days (range 165 days) for fish that died at sea. Fish that did not survive had lower weight/length ratios when tagged than survivors $(P=0.005)$ but exhibited a similar diel diving pattern while at sea. Both surviving and nonsurviving fish gradually increased diving activity and the daily visited maximum depths after sea entry, but some performed fewer dives and resided in shallower depths than others. This difference was pronounced when comparing surviving fish (most active divers) with fish caught by anglers (least active divers). The results show that the first weeks at sea are critical for kelt survival and that physical status of kelts may affect behaviour and probability of survival. The preference for shallower waters and less diving activity in some individuals indicate that coastally based fisheries and recreational angling may select against specific behavioural phenotypes which should be investigated more intensively.

\section{Key words:}

Sea trout; kelts; telemetry; survival; behaviour 33 5 


\section{Introduction}

The iteroparous nature of anadromous brown trout Salmo trutta L. (hereafter referred to as sea trout) allows individuals to enter freshwater multiple times to spawn (Klemetsen et al. 2003), and large repeat spawners may contribute with a disproportionately high production of juveniles (L'abée-Lund 1989). This makes survival and success of repeat spawners important for the overall success of a given brown trout population (Jensen et al. 2012). Spawning is energetically costly (Hendry et al. 2004), and the re-entry to marine environments may be associated with high mortality for post-spawned individuals (termed as kelts, Bendall et al. 2005; Thorstad et al. 2012; Aarestrup et al. 2015). Condition and physiology of kelts has been shown to affect their migratory behaviour during this phase (Bordeleau et al. 2018; Birnie-Gauvin et al. 2019). Part of a decline in sea trout populations observed worldwide may be attributed to reduced marine survival (Butler and Walker, 2006; ICES 2013) but detailed reports on kelt mortality at sea have not been published so far (Thorstad et al. 2016). Studies have found overall marine survival of sea trout kelts ranging from 18 to $86 \%$ with high mortalities in the early marine habitats like fjords and estuaries while mortality at sea is unknown (Bendall et al. 2005; Bordeleau et al. 2018). It is estimated that $32 \%$ of sea trout smolts produced in Denmark eventually end up dying as a consequence of recreational angling from the coast or in rivers (Nielsen and Koed 2016). Predators may also play a crucial role in sea trout mortality in the early marine environment (Jepsen et al. 2018; Kristensen et al. 2018a) but their impact on kelts is unknown. Danish (Aarestrup et al. 2015), Swedish (Aldvén et al. 2015) and British (Bendall et al. 2005) sea trout generally migrate to sea in a relatively direct manner as opposed to their more northern conspecifics (e.g. Eldøy et al. 2015; Jensen et al. 2014) and knowledge of aspects related to their mortality at sea are therefore important for the management of the species (Drenner et al. 2012).

We therefore tagged 125 sea trout kelts with positively buoyant data storage tags (DSTs). This enabled us to recover tags from fish that had died at sea (hereafter referred to as fish lost at sea) and compare the observed behaviour in these with the behaviour in surviving individuals (hereafter referred to as returning 
fish). The tagged fish had survived at least one successful marine period and were large in size compared to adult sea trout studied in marine environments elsewhere (e.g. Bendall et al. 2005; Rikardsen et al. 2007; Eldøy et al. 2015). The DSTs measured depth and temperature, and the aim of the study was to compare these measurements to document behavioural traits in returning fish and fish lost at sea to reveal possible differences between the two groups. We hypothesized that fish lost at sea would display different activity levels and migratory tactics than returning fish.

\section{Methods}

\subsection{Experimental area}

The fish were caught and tagged in seven Danish rivers (Figure 1). Five of the rivers ran into fjords or estuaries with outlets to either the southern North Sea or the Kattegat while rivers Liver and Uggerby ran directly into the Skagerrak (Table 1, Fig 1.).

\begin{tabular}{ccccc}
\hline River & Runs into & $\begin{array}{c}\text { River mouth } \\
\text { to sea outlet }\end{array}$ & $\begin{array}{c}\text { Outlet } \\
\text { location }\end{array}$ & $\begin{array}{c}\text { Tagged } \\
\text { individuals }\end{array}$ \\
\hline Ribe & Estuary & $14.9 \mathrm{~km}$ & North Sea & 4 \\
Varde & Estuary & $13.6 \mathrm{~km}$ & North Sea & 39 \\
Skjern & Estuary & $19.1 \mathrm{~km}$ & North Sea & 3 \\
Uggerby & Sea & $0 \mathrm{~km}$ & North Sea & 10 \\
Liver & Sea & $0 \mathrm{~km}$ & North Sea & 40 \\
Villestrup & Fjord & $22.1 \mathrm{~km}$ & Kattegat & 13 \\
Gudenaa & Fjord & $31.7 \mathrm{~km}$ & Kattegat & 16 \\
\hline
\end{tabular}

Table 1. River information. The distance from the river outlet to the sea, name of the sea of entry and the number of fish tagged in each river is given.

The seas surrounding Denmark are generally shallow with depths of 10-30 meters dominating the southern parts of the Kattegat and North Sea, while depths exceeding 100 meters can be found in the Northern North Sea, in Skagerrak and in the central Baltic Sea (Figure 1). A complex mixing regime and an almost constant stratification is present in the Kattegat-region due to differences in salinity between the saline 
North Sea (32-35 on the Practical Salinity Scale) and the brackish Baltic Sea (8-10 on the Practical Salinity

Scale) (Rasmussen 1995).

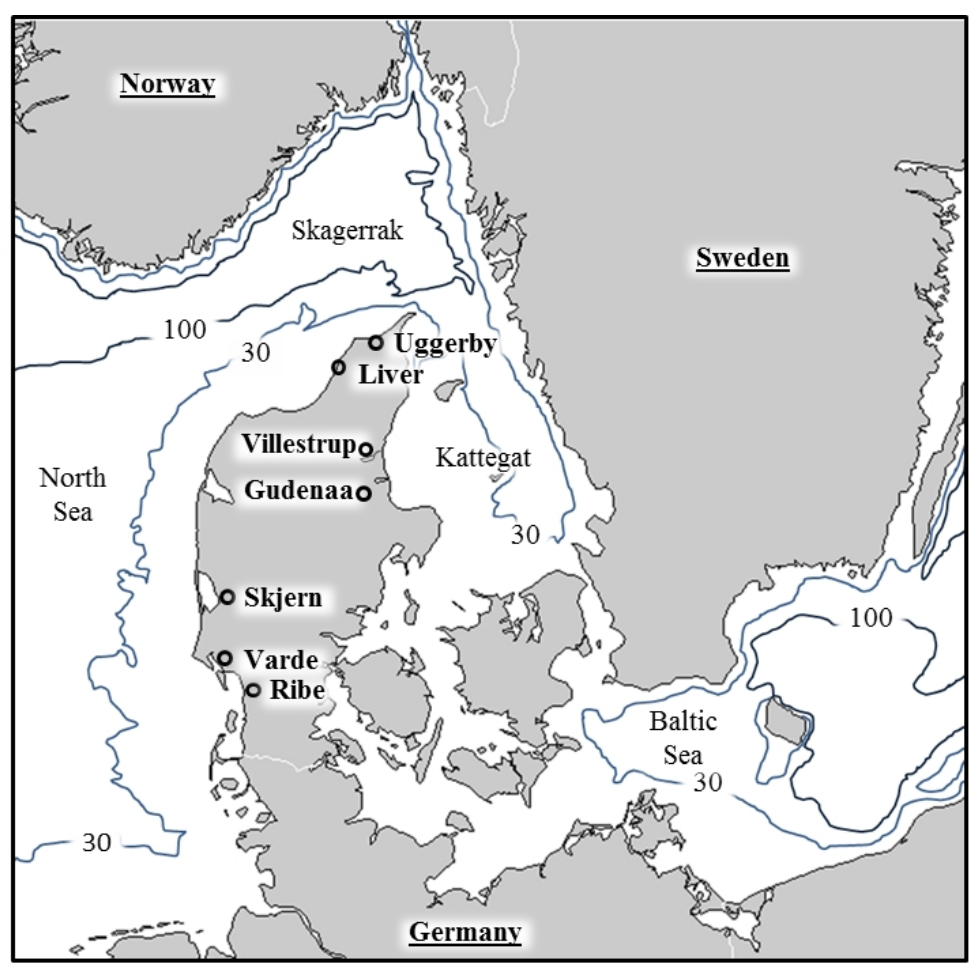

82

\subsection{Data storage tags}

Figure 1. Maps of the study area with depth contour lines for 30 and 100 metres (left panel). Open circles represent the location of the seven rivers where tagging took place. The 27 crosses on the right panel represent the pickup or capture location of the 25 recovered tags from fish lost at sea and the two corrupted tags that were found outside rivers and fjords.

We used CEFAS Technology Ltd G5 long life archival tag (http://www.cefastechnology.co.uk/) fitted with a string of $11 \mathrm{~mm}$ diameter floats (the same diameter as the tag). Total length with floats was approximately $140 \mathrm{~mm}$, weight in air was $9.8 \mathrm{~g}$ and the net buoyancy in full salinity sea water was $0.009 \mathrm{~N}$, corresponding to a negative weight in water of $0.9 \mathrm{~g}$. The floating device was covered in silicon rubber (Dow Corning, 734) that is biologically inactive and harmless to the fish (Thorstad et al. 2013). The tag type has not been used in salmonids before, but studies of tagged European eel (Anguilla anguilla) found only few cases of partial tag expulsion (12\%, but none were actually expulsed) after six months (Thorstad et al. 2013). 
The tags were programmed to record temperatures and pressure at 5-min intervals. Internal tag memory was sufficient to record a two-year period. Temperature range for the tags was $-5 \mathrm{C}$ to $35^{\circ} \mathrm{C}$ with an accuracy of at least $0.1^{\circ} \mathrm{C}$ and resolution of $0.03^{\circ} \mathrm{C}$. Pressure, a proxy for depth, was measured in dbars (1 dbar is equivalent to approximately $1 \mathrm{~m}$ in depth) to a maximum of $2000 \mathrm{dbars}$ and an accuracy of $\pm 1 \%$ $(20 \mathrm{~m})$ and resolution of $8 \mathrm{~cm}$. Tags were fitted with a reward notice and address asking people to return the tag upon recovery. Data was downloaded from the tags on their return.

\subsection{Fish capture and tagging}

Sea trout kelts were electro-fished or captured in traps during downstream migration in the rivers during winter or spring (Table 2). The fish were anaesthetized (benzocaine $300 \mathrm{ppm}$ ) and the total body length and body mass was measured. The DST was inserted into the body cavity through a mid-ventral $(8-10 \mathrm{~mm})$ incision anterior to the pelvic girdle. The incision was closed with 2-3 separate sutures. The operation lasted between 1 and $2 \mathrm{~min}$ and the recovery time was 2-5 min. The tagging process was carried out in accordance with the guidelines described in permission 2012-DY-2934-00007 from the Danish Experimental Animal Committee.

In total, 125 kelts were tagged: 45 were tagged November 28th and December 12th 2012, while the remaining 80 kelts were tagged between March 13th and April 13th in the years 2012-2015.

Tagging data from fish that died before sea entry are presented in Table S1.

\begin{tabular}{llccccccccc}
\hline Tag ID & Type & Origin & $\begin{array}{c}\text { Weight } \\
\text { (g) }\end{array}$ & $\begin{array}{c}\text { Length } \\
\text { (cm) }\end{array}$ & $\begin{array}{c}\text { Fulton's } \\
\text { condition }\end{array}$ & $\begin{array}{c}\text { Gender } \\
\text { conate of } \\
\text { tagging }\end{array}$ & $\begin{array}{c}\text { Date of sea } \\
\text { entry }\end{array}$ & $\begin{array}{c}\text { Marine } \\
\text { period } \\
\text { (d) }\end{array}$ \\
\hline A08546 & Returning & Liver & 7150 & 91.5 & 0.93 & $\mathrm{~F}$ & $16-03-2012$ & $27-04-2012$ & 47 \\
A08609 & Returning & Varde & 1650 & 54 & 1.05 & $\mathrm{~F}$ & $08-04-2013$ & $10-04-2013$ & 94 \\
A08634 & Returning & Varde & 1650 & 57 & 0.89 & $\mathrm{~F}$ & $08-04-2013$ & $14-04-2013$ & 87 \\
A08579 & Returning & Gudenaa & 1850 & 56.5 & 1.03 & $\mathrm{M}$ & $27-03-2013$ & $24-04-2013$ & 105 \\
A08534 & Returning & Gudenaa & 2400 & 58 & 1.22 & $\mathrm{~F}$ & $27-03-2013$ & $02-05-2013$ & 89 \\
A08577 & Returning & Liver & 1736 & 55 & 1.03 & $\mathrm{M}$ & $12-12-2012$ & $06-05-2013$ & 142 \\
A08549 & Returning & Gudenaa & 2480 & 58 & 1.27 & $\mathrm{~F}$ & $27-03-2013$ & $09-05-2013$ & 87 \\
A08640 & Returning & Villestrup & 1860 & 60.5 & 0.84 & $\mathrm{~F}$ & $13-04-2015$ & $28-04-2015$ & 118
\end{tabular}




\begin{tabular}{|c|c|c|c|c|c|c|c|c|c|}
\hline $\begin{array}{l}\text { Mean, } \\
\text { returning } \\
\text { fish }\end{array}$ & & - & 2597 & 61.4 & 1.03 & - & - & - & 96.1 \\
\hline A08565 & Lost & Ribe & 2525 & 67 & 0.84 & $\mathrm{~F}$ & $14-03-2012$ & 05-04-2012 & 19 \\
\hline A08563 & Lost & Liver & 4900 & 82.5 & 0.87 & $\mathrm{~F}$ & 16-03-2012 & $10-04-2012$ & 5 \\
\hline A08553 & Lost & Liver & 3190 & 71 & 0.89 & $\mathrm{~F}$ & $16-03-2012$ & $14-04-2012$ & 4 \\
\hline A08539 & Lost & Liver & 1130 & 53 & 0.76 & $\mathrm{~F}$ & $16-03-2012$ & $20-04-2012$ & 18 \\
\hline A08544 & Lost & Ribe & 1296 & 53 & 0.87 & $\mathrm{~F}$ & $14-03-2012$ & $20-04-2012$ & 2 \\
\hline A08636 & Lost & Varde & 1550 & 58 & 0.79 & $\mathrm{~F}$ & 08-04-2012 & $20-04-2012$ & 10 \\
\hline A08643 & Lost & Liver & 3159 & 78 & 0.67 & $\mathrm{~F}$ & $28-11-2012$ & $17-12-2012$ & 20 \\
\hline A08573 & Lost & Liver & 3630 & 75.5 & 0.84 & $\mathrm{~F}$ & 28-11-2012 & $18-12-2012$ & 2 \\
\hline A08758 & Lost & Uggerby & 2082 & 62 & 0.87 & $\mathrm{~F}$ & $12-12-2012$ & $21-12-2012$ & 9 \\
\hline A08576 & Lost & Liver & 1289 & 54 & 0.81 & $\mathrm{~F}$ & $12-12-2012$ & 03-01-2013 & 1 \\
\hline A08762 & Lost & Liver & 2150 & 62.5 & 0.88 & $\mathrm{~F}$ & $12-12-2012$ & $15-01-2013$ & 65 \\
\hline A08620 & Lost & Varde & 3900 & 73 & 1.00 & $\mathrm{~F}$ & 08-04-2013 & $13-04-2013$ & 17 \\
\hline A08601 & Lost & Varde & 2600 & 62 & 1.09 & $\mathrm{~F}$ & 08-04-2013 & $15-04-2013$ & 10 \\
\hline A08615 & Lost & Varde & 2620 & 64 & 1.00 & $\mathrm{~F}$ & $10-04-2013$ & 03-05-2013 & 46 \\
\hline A08590 & Lost & Varde & 1900 & 59 & 0.93 & $\mathrm{~F}$ & 08-04-2013 & 05-05-2013 & 17 \\
\hline A08552 & Lost & Gudenaa & 1750 & 55 & 1.06 & $\mathrm{~F}$ & 27-03-2013 & $11-05-2013$ & 2 \\
\hline A08556 & Lost & Varde & 1823 & 57 & 0.98 & $\mathrm{~F}$ & 04-04-2014 & 05-04-2014 & 22 \\
\hline A08576 & Lost & Varde & 2305 & 66 & 0.80 & $\mathrm{~F}$ & 03-04-2014 & 06-04-2014 & 16 \\
\hline A08565 & Lost & Varde & 3508 & 74 & 0.87 & $\mathrm{~F}$ & 04-04-2014 & 07-04-2014 & 3 \\
\hline A08556 & Lost & Villestrup & 3488 & 73 & 0.90 & $\mathrm{~F}$ & 06-05-2015 & $13-05-2015$ & 11 \\
\hline A08605 & Lost & Villestrup & 902 & 49.5 & 0.74 & $\mathrm{~F}$ & $13-04-2015$ & 23-05-2015 & 1 \\
\hline $\begin{array}{c}\text { Mean, } \\
\text { fish lost } \\
\text { at sea }\end{array}$ & & - & 2462 & 64.2 & 0.88 & - & - & - & 14.3 \\
\hline A08549 & Angled & Skjern & 4070 & 78 & 0.86 & $\mathrm{~F}$ & $13-03-2012$ & 04-04-2012 & 26 \\
\hline A08640 & Angled & Varde & 4220 & 74 & 1.04 & $\mathrm{~F}$ & 08-04-2013 & $17-04-2013$ & 42 \\
\hline A08758 & Angled & Villestrup & 1539 & 60.3 & 0.70 & $\mathrm{~F}$ & 27-03-2015 & $18-04-2015$ & 8 \\
\hline A08543 & Angled & Villestrup & 1526 & 54.5 & 0.94 & $\mathrm{~F}$ & 27-03-2015 & 07-06-2015 & 75 \\
\hline $\begin{array}{c}\text { Mean, } \\
\text { fish } \\
\text { angled at } \\
\text { sea }\end{array}$ & - & - & 2839 & 66.7 & 0.89 & - & - & - & 37.8 \\
\hline
\end{tabular}

111 Table 2. Tagging data for the eight returning fish, the 21 fish lost at sea due to unknown causes and the four fish caught by anglers

112 from the coast. The table contains tag ID, origin of the fish, weight, length, condition, gender, date of tagging and sea entry along

113 with marine period. Fulton's condition is given by $K=100 \frac{\operatorname{Weight}(\mathrm{g})}{\operatorname{Length}(\mathrm{cm})^{3}}$.

$114 \quad 2.4$ Determining the duration of the marine period

115 Internal temperature and depth recorded by the recovered DSTs were downloaded from the tags and

116 analysed in R Studio version1.0.136 (www.r-project.org). 
Time of entry and exit to the marine environment was based on analysis of depth measurements. The fish appeared to initiate the dive pattern described in Kristensen et al. (2018b) when reaching the marine environment. Some of the fjords and estuaries entered by the fish in the present study are, however, only a few metres deep, making it impossible for the fish to initiate the behaviour before reaching deeper waters. It was therefore not possible with certainty to segregate between residency in rivers or marine environments before the fish entered areas with deeper waters. We therefore focused on the sea, and defined entry to and exit from the sea as the period between the first and last visit to a depth of 10 metres. All fjords and estuaries except the fjord that River Villestrup runs into are shallower than this (a threshold of 15 metres was used for fish from this river).

In some cases, fish would initiate their dive/surface residency behaviour with dives to 5-10 meters for 1-4 days before breaking the 10 metre threshold (Figure S1), indicating that the fish had entered the sea but was not yet residing in areas with depths exceeding 10 metres. Close inspection of temperature data for all fish revealed a decline in surface temperatures 0-4 days before sea entry (defined by the 10 metre threshold), suggesting that the fish may have entered the sea 0-4 days sooner. We maintained the uniform definition of first and last visit to a depth of 10 metre in spite of the possible 0-4 days of error associated with doing so in order to maintain an unbiased data treatment.

\subsection{Determining mortality events}

134 Time of mortality of fish lost at sea was defined by visual inspection of temperature and depth plots. In 135 three tags, temperatures increased to $37^{\circ} \mathrm{C}$ for $1-2$ days, suggesting that the tags had been ingested by a marine mammal (Figure 2a). Eight tags sunk to the bottom and recorded small cyclic depth changes caused by the tide (Figure $2 b$ ), suggesting that the tag had sunk with the fish or parts of it. Thirteen tags reported a constant depth of 0 metres (Figure $2 c$ ), leaving few clues as to the cause of mortality. 

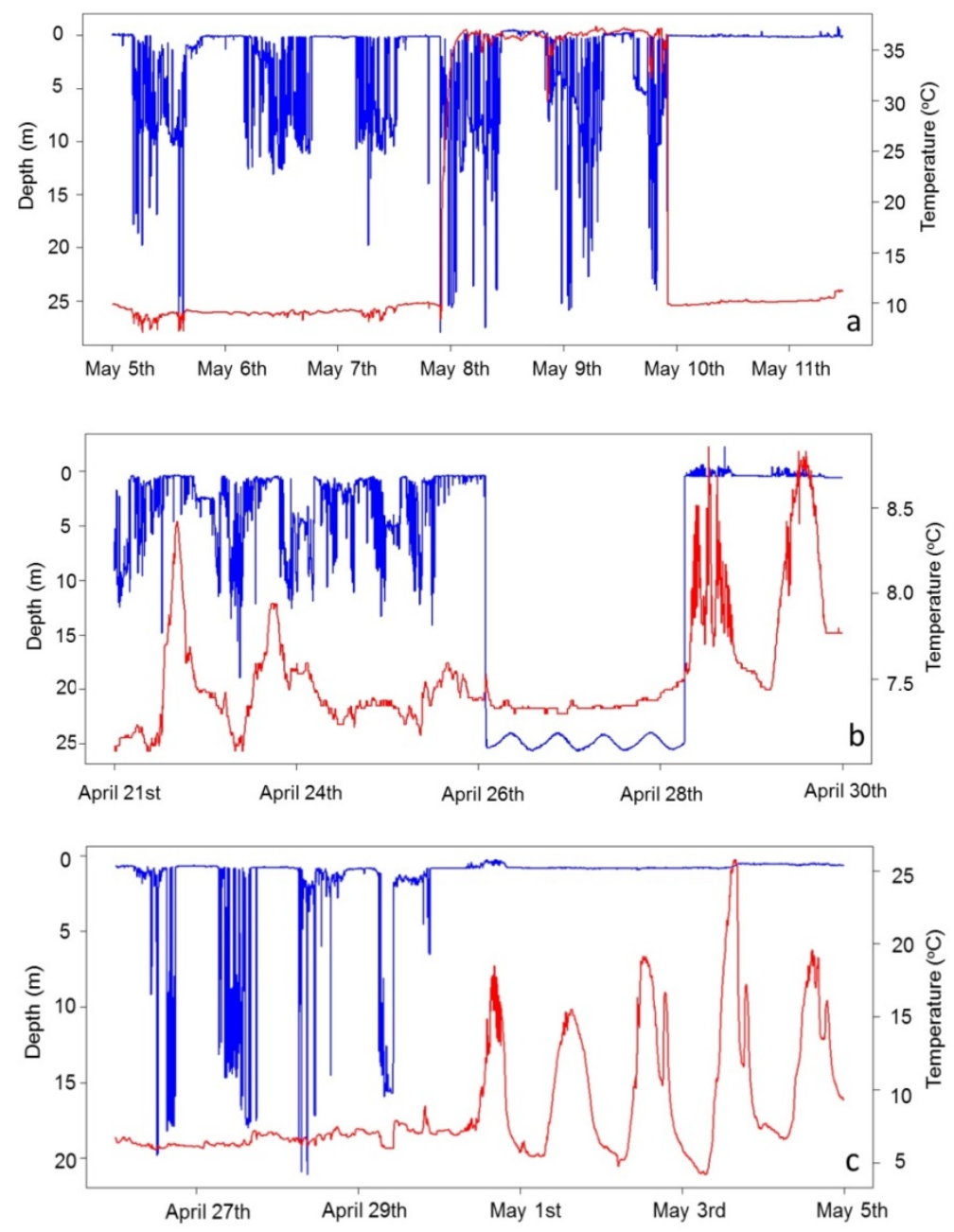

140 Figure 2. Examples of mortality events with depth (blue line) and temperature (red line) records of different mortality profiles. 2a:

141 Temperature increases to $37^{\circ} \mathrm{C}$ and returns to ambient levels 1-2 days later, suggesting marine mammal predation. $2 \mathrm{~b}$ : The tag 142 drops to the bottom where it records tidal amplitudes for two days before returning to the surface. 2c: Recorded depths suddenly

143 stabilizes at $0 \mathrm{~m}$ until the tag reaches shore a day later (temperature starts fluctuating).

144 The timing of mortality was easily distinguishable with a precision of a few measurements ( $<15$ minutes) for 14523 of the 25 recorded mortalities. For the remaining two records, it was hard to determine with accuracy when mortality occurred as the fish was resident very close to the surface around the time of death.

148 All individuals appeared to initiate a characteristic diving pattern (Kristensen et al. 2018b) once they reached the sea. The present study follows the definition of a dive that was used by Reddin et al. (2011) 
and Kristensen et al. (2018b) where a dive is defined as an entry to depths deeper than 5.0 metres, and each dive is logged at the time of the first measurement in depths deeper than 5.0 metres. The duration of the dive is determined by the number of subsequent measurements at depths deeper than 5.0 metres, while the dive is defined as terminated once the fish enters depths shallower than 5.0 metres again.

\subsection{Data analysis}

Weight/length relationships between different groups of fish were analysed with general linear models where weight of the fish in grams was entered as response variable and length and type of fish were entered as explanatory variables. Both weight and length were square root transformed to linearize the relationship and to ensure model assumptions were met.

Generalised linear mixed effects models were used to analyse if returning fish behaved differently compared to fish caught by anglers and fish lost at sea in terms of daily dive frequency and daily maximum depths at sea. Only four fish were caught by anglers at sea, which technically is too few to include as a separate group. The models, however, displayed some behavioural differences between the groups well, and fish caught by anglers were therefore included as a separate group to illustrate this.

The models included data from the first 20 days at sea, as most fish lost at sea died within this period. The 33 fish that entered the sea are divided into four groups: Returning fish (group 1, $n=8$ ), lost fish where the tag started floating after mortality or the fish was predated (group $2, n=13)$ ), lost fish where the tag sunk to the bottom after mortality (group 3, $n=8$ ) and fish caught by anglers (group 4, $n=4$ ).

A negative binomial generalised linear mixed effects model was used to analyse for differences in diving frequencies among the four groups of fish. Number of dives per day was entered as response variable while days since marine entry and fish mortality type were entered as fixed effects and fish ID was entered as random effect. Negative binomial was used for the amount of dives per day since the conditional variance exceeded the conditional mean in Poisson-regression models due to high variation of the diving activity. 
173 Model diagnostic by visual inspection of residuals plotted against the data showed no signs of violation of

174 model assumptions. The dispersion statistics of the model was 1.06, revealing no signs of over- or

175 underdispersion of the model (Zuur et al. 2009).

176 A gamma distributed generalised linear mixed effects model with a log link was used to analyse for

177 differences in daily visited max depth among the four groups of fish. Daily depths were entered as response

178 variable while days since marine entry and fish mortality type were entered as fixed effect and fish ID was

179 entered as random effect. The diagnostics of this model showed no patterns when residuals were plotted 180 against the data.

181 The R-package glmmTMB (Brooks et al. 2017) was used to run the models.

182 3. Results

$183 \quad 3.1$ Tag return rates

184 Six of the eight tags from returning fish were recovered by recreational anglers who caught the fish after it

185 had returned to the river. The seventh tag from a returning fish was recovered after the fish was electro

186 fished for stocking efforts while the eighth tag from a returning fish was found on the river bank (without

187 the fish).

188 Seven of the 21 tags from fish lost at sea were found along Danish shorelines, nine tags were found along

189 Swedish coastlines and the remaining five tags were found along Norwegian coastlines (Figure 1).

190 All five tags that contained corrupted data were found in the water or along coastlines. 


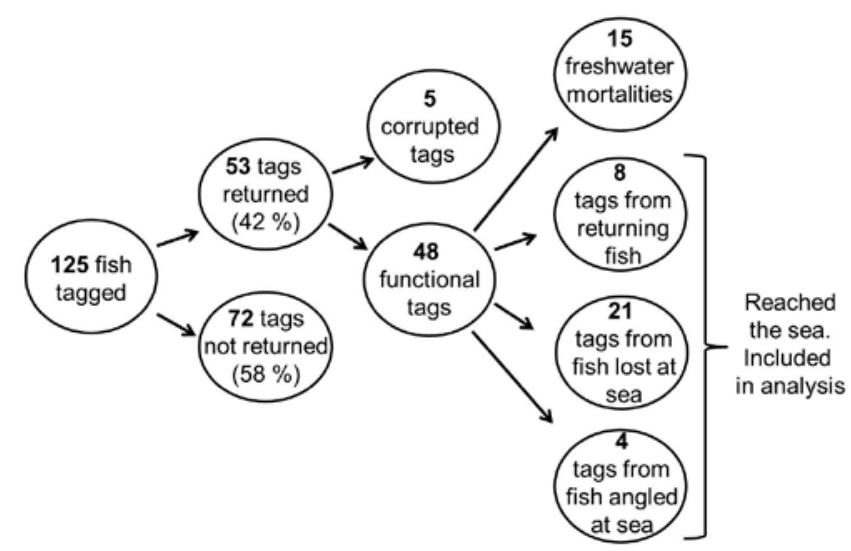

Figure 3. Fate of the 125 tags. In total, 33 tags had recorded fish behaviour from the sea.

194 Inspection of the data from the 21 fish lost at sea but where mortality reasons were unknown (as

195 exemplified on Figure $2 \mathrm{~b}$ and $2 \mathrm{c}$ ) suggested that the tags had been drifting in the water for a mean period

196 of 24 days (range: 0 - 101 days) before reaching shore. Some tags were found almost instantly after

197 reaching shore, while extensive temperature fluctuations suggested that other tags had been deposited on

198 dry land for weeks or months before recovery.

\subsection{Size and condition of the fish}

200 The mean weight of all 125 tagged fish was $2640 \mathrm{~g}$ (range: $760-7250 \mathrm{~g}$ ), the mean length was $65.3 \mathrm{~cm}$

201 (range: $46.0-92.5 \mathrm{~cm}$ ) and the mean Fulton's condition was 0.88 (range: $0.66-1.28$ ). Fulton's condition is

202 given by $K=100 \frac{\text { Weight }(\mathrm{g})}{\text { Length }(\mathrm{cm})^{3}}$. The distribution of the tagged fish is presented in Figure 4.
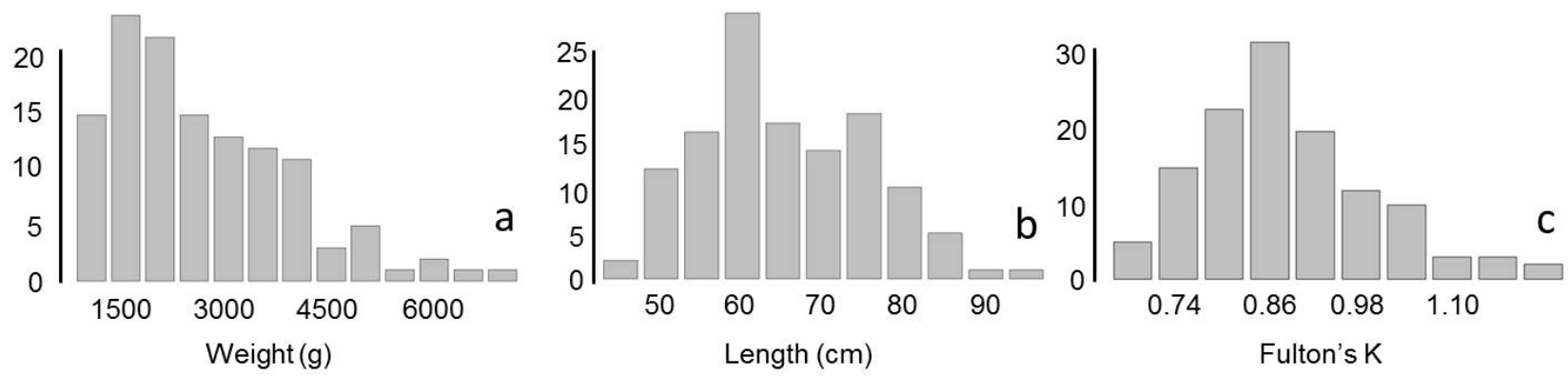
Figure 4. Distribution of the 125 tagged fish. 4a: Weight (g) of the fish in $500 \mathrm{~g}$ intervals. $4 \mathrm{~b}$ : Length of the fish (cm) in $5 \mathrm{~cm}$ intervals, 4c: Fulton's K in intervals of 0.06.

Mean weight of the 72 fish where tags were not returned and the 53 fish where tags were returned was identical $(2640 \mathrm{~g}$ ) while mean length was nearly identical $(65.3 \mathrm{~cm}$ for fish with non-returned tags and 65.2 $\mathrm{cm}$ for fish with returned tags). The weight/length relationship for the two groups of fish displayed on Figure 5a was not significantly different according to the general linear model $\left(P=0.24, R^{2}=0.91\right)$.

The present study mainly focuses on comparison of the eight returning fish, the 21 fish that were lost at sea and the four fish that were caught by anglers at sea. Fish lost at sea at had a significantly lower weight/length relationship $(P=0.005)$ than returning fish. Fish caught by anglers were similar to fish lost at sea, but the difference between fish caught by anglers and returning fish came out with a higher P-value of was 0.93 .
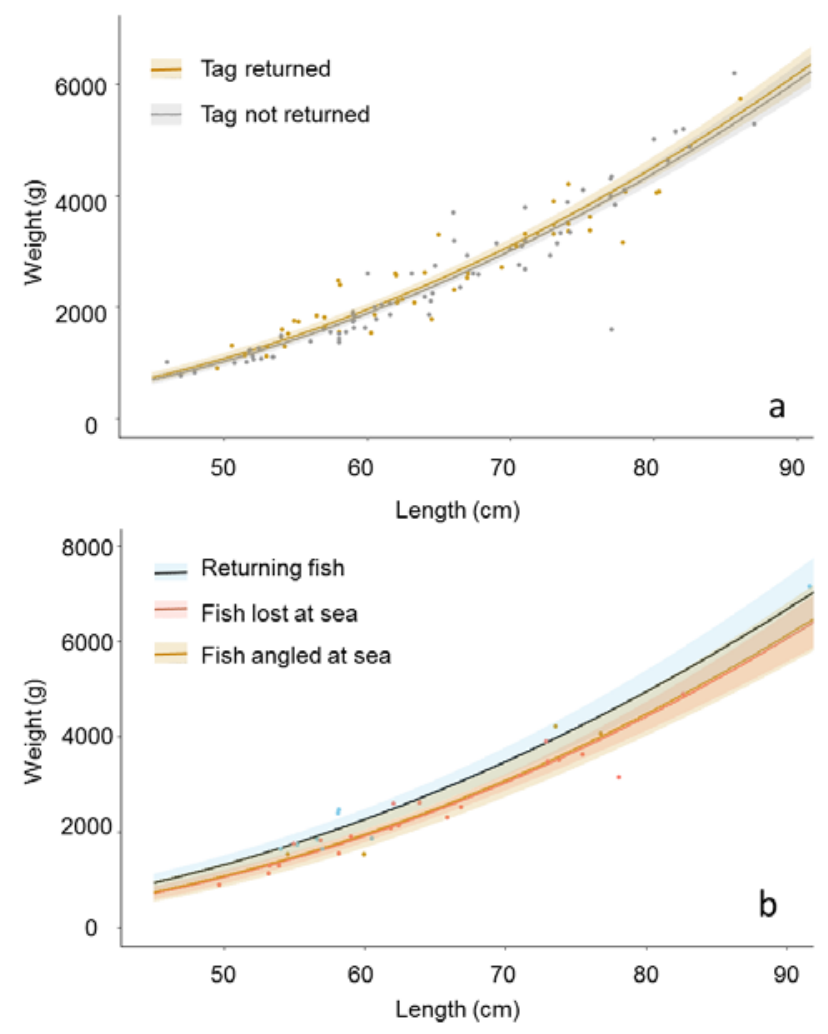
Figure 5. Linear model of weight/length relationship for different groups of fish. Shaded areas represent $95 \%$ confidence intervals and points represent individual fish. 5a: Fish where the tag was returned vs. fish where it was not. 5b: Returning fish vs. fish lost at sea and fish caught by anglers at sea.

\subsection{Survival and duration of marine period}

Fifteen returned tags contained data suggesting mortality prior to sea entry. Eight of these tags did not record depths greater than 2.0 metres before the fish died, while four recorded max depths between 2-9 metres before fish mortality, suggesting that the fish could have reached the fjord or estuary. The remaining three tags had recorded max depths between 2-8 metres before the fish that carried them were caught by anglers in the fjords. A total of seven kelts could therefore have reached the marine environment without entering the sea before mortality.

The present study only analyses data from fish that certainly made it to sea (based on the 10 metre threshold). It therefore disregards these seven fish that either could have or certainly did reach the marine environment due to the uncertainty associated with their fate and possible timing of marine entry. Including these seven fish in the analyses does not change the output and conclusions, but it introduces additional uncertainty.

The tagged fish spent a mean of 26.3 days (range: 1-142 days) in the river or fjord/estuary between tagging and sea entry. Fish lost at sea spent a mean of 22.0 days (range: 1-72 days) in river/fjord/estuary before entering the sea, and survived for a mean period of 40.0 days (range: 6-99 days) after tagging.

Mean duration of the period spent at sea for the eight returning fish was 96.1 days (range: $47-142$ days, Table 2), while fish caught by anglers survived 37.8 days (range: 8-75 days) at sea and fish lost at sea survived 14.3 days (range: 1-65 days) at sea. It was not possible to determine the duration of the marine period (including fjords/estuaries) with the present dataset. Using kelt movement rates of Aarestrup et al. 
fjords on estuaries adds 6.4 days to the mean time spent at sea, resulting in a mean marine survival time of 20.7 days for the present dataset.

Three of 21 natural mortalities at sea had mortality profiles similar to Figure 2a, where a warm blooded animal presumably ingested the tag. Eight mortality profiles were similar to Figure $2 \mathrm{~b}$, where the tag sunk to the bottom for a period of time and 10 mortalities were similar to Figure $2 \mathrm{c}$ where the tag started 245 floating.

Of 21 natural mortalities at sea, 19 could be determined with a precision of 5-10 minutes. Eight of these mortalities (42\%) occurred during daytime, seven (37\%) occurred within one hour from sunrise and sunset and four mortalities ( $21 \%$ ) occurred during nighttime. Mean day length on the day of mortality was 13.7 hours for the 19 precisely determined natural mortality events at sea, corresponding to a mean of $57 \%$ daytime, $17 \%$ crepuscular hours and $26 \%$ nighttime at the time of death. The three recorded predation events from warm-blooded animals occurred during daytime $(n=1)$ or crepuscular hours $(n=2)$.

\subsection{Behaviour at sea}

All fish exhibited a distinct diel behavioural pattern with pronounced diving activity during daytime and residence close to the surface with very little vertical movement during night time (Figure 6). Although large variation occurred between individuals and in time, the typical pattern was for the fish to perform a dive of 10-25 minutes duration and return to shallow depths of 0-3 metres for 30-40 minutes before diving again. The behaviour has previously been described for the returning fish of the present study by Kristensen et al. (2018b). Most dives peaked at depths between 10-20 metres, though the record dive of the dataset was 88 metres. Some individuals only rarely visited depths deeper than 10 metres, possibly due to dive depth restriction caused by the sea floor in the area of residence. 

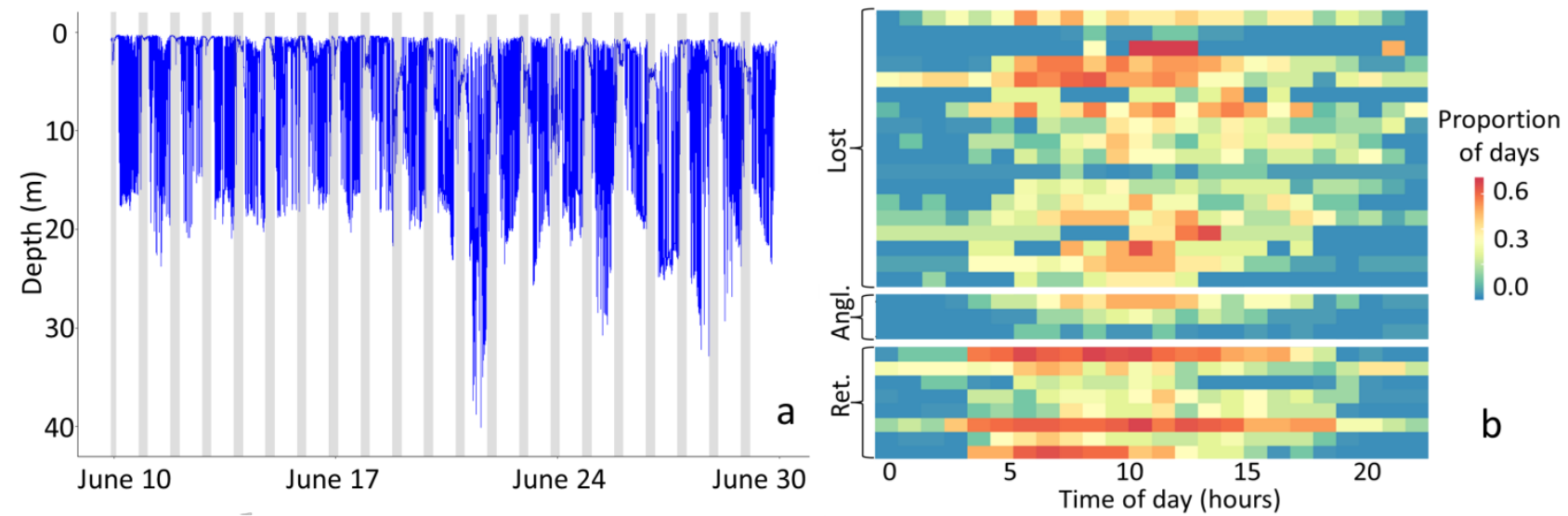

Figure 6. a) Example of diel behaviour during June 2013 with depth (blue line) of a returning fish (A08549) where shaded areas represent night time (20-04 hours). Note how the fish dives repetitively during daytime but is almost constantly residing at the surface during nighttime b) Proportion of the 20 first days at sea where each individual fish performed at least one dive during a given hour of day. The eight rows in the bottom represent returning individuals, the next four rows are fish caught by anglers and the top 17 rows are fish lost at sea. The blue colours dominating before 4 and after 19 hours reveal that the fish generally perform few or no dives during evening and night time while the yellow and orange colours between 4 and 19 hours reveal that the fish dive more frequently during these hours. Four fish resided $<3$ days at sea before dying and are not included.

The fish caught by anglers were the least active in terms of diving activity and had also resided at the most shallow depths (Figure 7). The diving activity generally increased with time after sea entry for all fish. Mean number of dives per day for all kelts was 14.3 (range: $2.3-27.2$ ). 

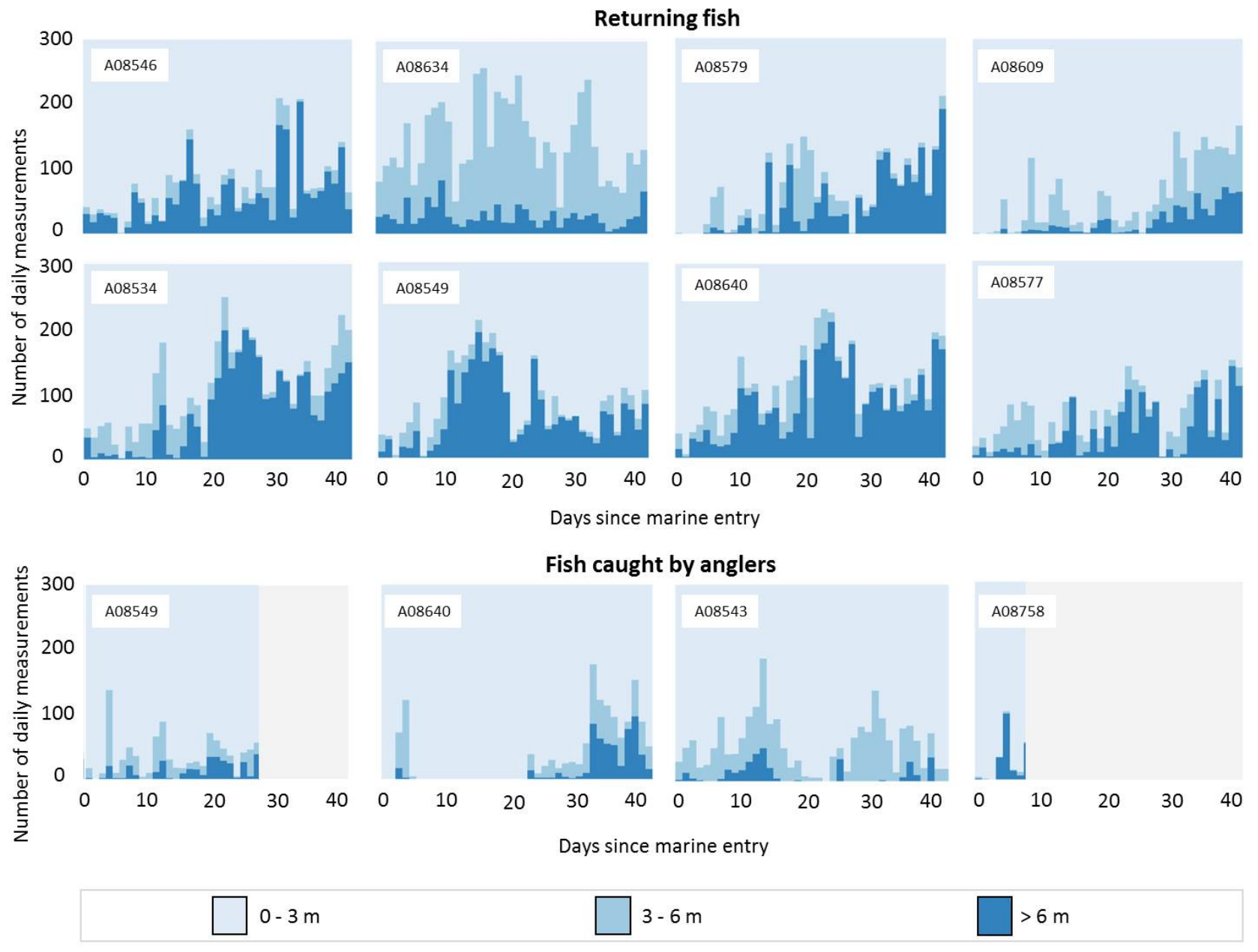

$3-6 m$

$>6 \mathrm{~m}$

Figure 7. Histograms of daily measurements at depths of 0-3 m (light blue), 3-6 m (medium blue) and deeper than $6 \mathrm{~m}$ (deep blue) for returning and fish caught by anglers during the first 40 days at sea. Fish caught by anglers reside more in shallow (0-3 $\mathrm{m})$ waters than returning fish, thus suggesting that these fish were more likely to get caught in the first place due to the high coastally based fishing pressure in the area.

We investigated the diving activity and daily visited max depth with generalized linear mixed models, although the sample size of the fish caught by anglers was not sufficient for an ideal investigation of this. $<2 \mathrm{e}^{-16}$, Table 3). 

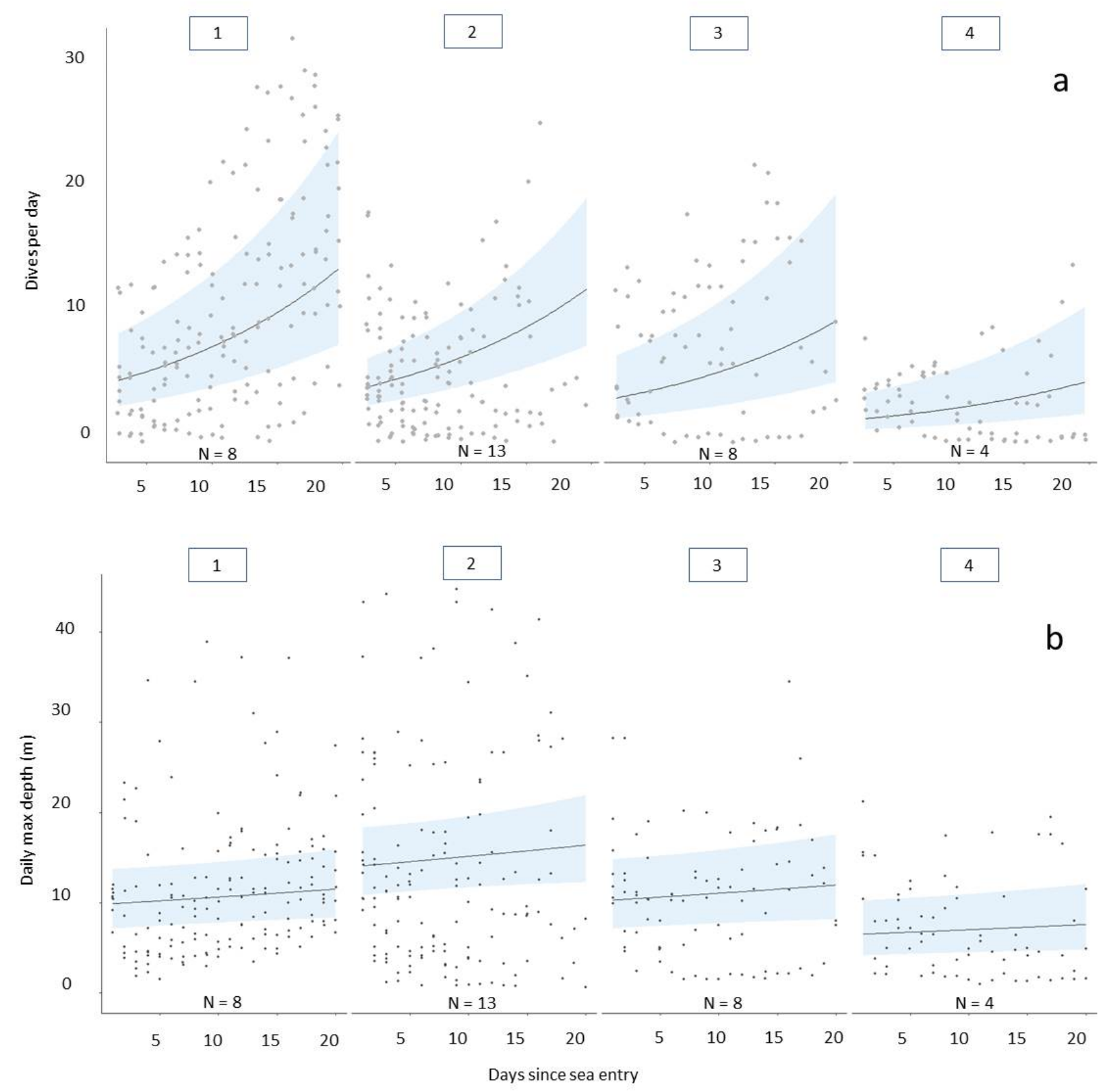

Figure 8. Modelled daily dives since sea entry (8a) and daily visited max depth (8b) for returning fish (1), fish lost at sea where the tag floated immediately after mortality (2), fish lost at sea where the tag sunk after mortality (3) and fish caught by anglers (4). Shaded areas represent $95 \%$ confidence intervals of the model, while points represent actual observations. Diving activity is higher for returning fish and gradually increases for all types after marine entry though less pronounced for fish caught by anglers. The fish caught by anglers also visited more shallow max depths. 

marine entry, while the fish caught by anglers appeared to have visited the shallowest max depths (Table

$2913)$

Diving activity

\begin{tabular}{ccccc}
\hline & Value & SE & z-value & P \\
\hline Intercept & 1.989 & 0.300 & 6.638 & $<0.0001$ \\
Days at sea & 0.321 & 0.034 & -2.110 & $<0.0001$ \\
Returning & 0 & - & - & - \\
Lost, floats & -0.125 & 0.378 & -0.330 & 0.741 \\
Lost, sinks & -0.371 & 0.476 & -0.778 & 0.436 \\
Angler & -1.110 & 0.526 & -2.110 & 0.035
\end{tabular}

Max depths

\begin{tabular}{ccccc}
\hline & Value & SE & z-value & $\mathbf{P}$ \\
\hline Intercept & 2.285 & 0.169 & 13.546 & $<0.0001$ \\
Days at sea & 0.008 & 0.005 & 1.472 & 0.141 \\
Returning & 0 & - & - & - \\
Lost, floats & 0.353 & 0.206 & 1.714 & 0.087 \\
Lost, sinks & 0.039 & 0.242 & 0.162 & 0.872 \\
Angler & -0.415 & 0.276 & -1.502 & 0.133
\end{tabular}

Table 3. Summary of the mixed models analyzing diving activity and daily max depths for the first 20 days at sea. Model parameter estimates, associated SE, z-values and p-values are given. A negative binomial distribution was used for the diving activity while a gamma distributed model was used for maximum depths.

\section{Discussion}

Large repeat spawning sea trout may contribute with a disproportionately high production of juveniles (L'abée-Lund 1989) thus making them important for the overall success of a given brown trout population (Jensen et al. 2012). We used positively buoyant data storage tags to generate the first detailed records of behaviour in adult sea trout that either died at sea or survived their marine period and returned to spawn. Our aim was to investigate whether the two groups behaved similarly in terms of activity levels and migratory behaviour.

\subsection{Return rate and effects of the positively buoyant DSTs}

The $6.4 \%$ return rate (8/125 tagged fish) for tags from returning fish is low compared to other studies, while the total return rate of $42 \%$ (53/125 tagged fish) is within the normal ranges achieved by other studies relying on active recapture methods for non-floating DSTs as discussed by Kristensen et al. (2018b). 
The method of the present study was, however, mainly passive, and a total of 43 tags (34 \%) were returned by citizens who had found the tag without the fish. The floating characteristic of the tag therefore succeeded in enabling collection of a dataset with behavioural reports from both returning fish and fish lost at sea. This is unique compared to other DST-studies where the reported behaviour is based exclusively on surviving individuals and therefore does not contain analysis of behavioural differences between surviving and non-surviving fish.

The number of tags returned due to the floating characteristic is high compared to Righton et al. (2016) that is the only existing study in the literature to have used positively buoyant DSTs on other species and recovered $9 \%$ of tags from ocean-going European eels (Anguilla anguilla).

A tag with the size of the DSTs used in the present study could have affected both fish behaviour and survival, and the reported mortalities should therefore be considered a pessimistic estimate. The tagged fish were, however, post-spawned with plenty of room in the body cavity for the tag, and there were no reports on tag-related wounds or infections from fish that were caught alive. The fish lost at sea spent 22.0 days in river/fjord/estuary before entering the sea, and the distribution of recorded mortalities in this phase (31 \% or 15/48 recovered, non-corrupted tags) was below that observed in studies of kelts in Denmark using smaller acoustic tags. Aarestrup et al. (2015) recorded a loss of $37 \%$ in the river/fjord phase for kelts from the River Gudenaa using 29 mm tags. A study from 2017 and 2018 recorded a river/fjord loss of $62 \%$ in kelts from rivers entering a different fjord system (the Limfjord, Kristensen et al. 2019) using 13 $\mathrm{mm}$ tags.

A total of 17 tags were recovered from anglers who had caught the fish ( $n=3$ from rivers, $n=3$ from fjords, $\mathrm{n}=4$ from the sea, $\mathrm{n}=7$ from returning fish back in the river), none of which had observed tag related damage or disease in the fish. One of the returning fish was handed over for dissection, revealing no inflammatory response to the tag that had been encapsulated in tissue. We have therefore observed no 
particular negative effects related to using positively buoyant tags compared to other tag types, although future studies could ideally investigate this further.

The high early mortality at sea observed in the present study could in principle be due to the fish most

likely being closer to shore in the first weeks after reaching the sea (Kristensen et al. 2018b) if tags from fish that die here have a higher chance of being found. $67 \%$ of the tags that were found from fish lost at sea were, however, found on Swedish or Norwegian coastlines, most likely after being moved there by dominating $\mathrm{W}-\mathrm{SW}$ winds in the region. The mean drifting time from expel-time to reaching the shore was 24 days (range: 0 - 101 days), and tags therefore appeared to be capable of surviving marine conditions for long enough to reach shore and be found as long as the fish resided within the seas surrounding Denmark. The fish may have moved into open sea during July and August as suggested by Kristensen et al. (2018b) and Klemetsen et al. (2003) but likely not into the actual ocean as for Righton et al. (2016).

\subsection{Size and condition of the fish}

The size of the fish that were tagged in the present study $(46.0-92.5 \mathrm{~cm})$ have some size overlap with the kelts tagged by Aarestrup et al. (2015) that measured between 30 and $87 \mathrm{~cm}$. The fish were, however, considerably larger than adult sea trout studied outside Denmark, e.g. $27.5-58.0 \mathrm{~cm}$ in Eldøy et al. (2017) and $37.0-51.2 \mathrm{~cm}$ in Rikardsen et al. (2007). The difference is likely attributed to a general size difference 345 between Danish and more northern sea trout populations.

346 The low condition factor of the tagged fish (mean $=0.88$ ) reflects that only post-spawned individuals were 347 tagged to avoid spawning-related tag loss and to ensure that there was room for the tags in the body 348 cavities. The statistically significant difference $(P=0.005)$ between condition factor of returning fish (mean

$349=1.03$ ) and fish lost at sea (mean $=0.87)$ indicates that condition may influence chances of survival.

350 Other physiological parameters such as levels of cortisol stress hormones may also affect migration timing 351 according to a recent study including Danish sea trout kelts (Birnie-Gauvin et al. 2019). Further investigation 
of the effect of physiology on behaviour may therefore broaden our understanding of drivers behind migratory behaviour and survival chances in salmonids.

\subsection{Survival and duration of marine period}

355

Timing of outmigration to the sea is within the normal period for fish that migrated during spring (Aarestrup et al. 2015). Migration timing of the 45 fish tagged on November 28th or December 12th are incomparable, as no other published or unpublished studies on Danish sea trout kelts have tagged fish during that time of year.

The early marine stage is generally risky for downstream migrating salmonids, and high early mortality is frequently observed in the marine environment (Thorstad et al. 2016). The present study reinforces previous findings on kelt survival, but also adds to it because no previous studies have identified at-sea mortality events. The 15 fish ( $31 \%$ of the 48 returned, non-corrupted tags) that died before sea entry are the ones that should be compared with e.g. the early mortality of other studies, like the $37 \%$ in Aarestrup et al. (2015) and $38 \%$ in Bendall et al. (2005). Even these values are not entirely comparable, as the fish from rivers Liver and Uggerby entered the sea directly. Pre-sea mortality was, however, $26 \%$ for the remaining systems as river-mortality was quite high in rivers Liver and Uggerby. Biases related to the likeliness of people finding tags from dead fish in rivers versus fjords and the sea, however, means that the setup used in the present study is not ideal for determining mortality rates.

Early marine mortality appeared high with 19 of 21 mortalities (not including fish caught by anglers) occurring within the first 22 days after reaching the sea and mean survival time at sea being 14.3 days (excluding fish caught by anglers). Adding the calculated time spent in fjords and estuaries increases the marine survival time to 20.7 days excluding fish caught by anglers. This number is uncertain, but the first three weeks after entering the marine environment appears to be a critical period for Danish sea trout kelts. 
vitulina and grey seals Halichoerus grypus have become abundant in the seas surrounding Denmark (Larsen et al. 2015), and may potentially predate on sea trout kelts as appeared to have occurred for these three fish. Seals mainly hunt within $30 \mathrm{~km}$ from shore (McConnel et al. 1999, Tollit et al. 1998), and are therefore capable of covering most of the seas surrounding Denmark. Harbor porpoises Phocoena phocoena is another warm blooded predator that is present in the region, but these are not expected to catch prey items larger than $26 \mathrm{~cm}$ in size and are thus less likely to have predated on the trout kelts (Recchia and Read, 1989).

Eight tags sunk (supposedly with the fish or parts of it) after mortality, while ten tags floated immediately after mortality, suggesting the tag was no longer in the body cavity of the fish after the final measurement. We consider it unlikely that these are all tag expulsions, as the size of the tag and the floats used in the present study is quite large, and full expulsion were not documented in eels (Thorstad et al. 2013). Single incidents of expulsion could, however, have occurred. Seal-predation cannot be ruled out as the final fate of these fish either, as seals do not swallow large fish like sea trout kelts whole, but will tend to open the fish and eat parts of it (Larsen et al 2015). Fish sinking with the tag could also be a consequence of mortality due to energy depletion, infections or other late effects of spawning or the tagging procedure. trout from the coast is popular in Denmark, and $32 \%$ of produced wild sea trout are estimated to eventually end their life due to angling (Nielsen and Koed, 2016). This makes angling an important factor to consider in the management of the species.

\subsection{Behaviour at sea}

The behaviour with repetitive dives during daytime and a pause at the surface during night time described 397 for the returning fish in Kristensen et al. (2018b) was generally observed for all fish, although some of the 398 fish lost at sea fish had unstable diving patterns. The possibility that fish that die do not establish good diel 
movements and stay closer to the surface, thus making them more vulnerable to predators and anglers and potentially less able to find food, should be investigated further.

With 33 fish from seven Danish rivers following this diel behavioural pattern to a more or less pronounced degree, we hypothesise that this behaviour could be widespread for sea trout outside the arctic region where continuous light during summer may be responsible for the absence of diel patterns in sea trout there (Rikardsen et al. 2007).

Although not finally proven, the repetitive diving strategy observed in sea trout kelts of the present study and for other anadromous fishes in the Atlantic (Reddin et al. 2011) and Pacific (Walker et al. 2000) is likely related to foraging, thus making it important for acquiring food leading to success at sea. If the energetic status of the fish is too low to enable this behaviour, it may compromise the chance of survival. According to the GLMM, the number of dives per day increased with date after sea entry for all fish as in Reddin et al. (2011). Returning fish appeared to be more active, and were also significantly more active than fish caught by anglers.

This difference could be related to foraging strategy or predator avoidance and suggests that condition may affect migration behaviour as observed in Atlantic salmon in rivers by Halttunen et al. (2013) and in the marine environment as observed in sea trout by Bordeleau et al. (2018). In Bordeleau et al. (2018), fish condition was negatively correlated with the likeliness of it migrating to the outer parts of the fjord. The data from the present study were, however, not conclusive in this sense, possibly due to the complexity and general shallowness of the seas surrounding Denmark. A similar study with fish from a single river with direct access to a sea area with deep waters close to shore may be more suited for future investigation of differences in behaviour related to condition or physiological parameters.

The apparent preference for shallow depths and fewer foraging dives in some fish raises the possibility of angler and fisheries-induced selection due to the pronounced angling and fisheries efforts from coastlines in the region. Harvest based selection has been observed for other species (Philipp et al. 2008; Uusi- 
Heikkilä et al. 2008), and could over time affect the distribution of sea trout phenotypes and have negative effects for ongoing efforts to increase angling for sea trout from Danish coasts. The dataset from the present study is too small to determine if residency in shallow depths occurs randomly or is a particular preference of some individuals, thus possibly exposing sea trout to selection from coastal-based angling. A more confined study setup with fish from a single river in collaboration with people angling on nearby shorelines could generate a larger dataset on this.

In summary, we observed high early marine mortality in Danish sea trout kelts, consistent with other studies on salmonids, but we also recorded mortality in the sea after a considerable period of time had passed. Mortality appeared high for the first three weeks at sea, confirming that this period is critical for the survival of salmonid kelts. Fish caught by anglers or fish lost at sea due to natural reasons were in poorer condition when tagged than fish that survived the marine period and returned to the rivers again.

Once in the sea, the fish gradually increased their diving activity and to some extent also their daily visited max depths. Surviving fish appeared to be more active than non-surviving fish in terms of diving activity, which was particularly true when comparing with non-surviving fish caught by anglers that had also preferred residency on shallower depths. This is the first study to provide detailed behavioural data of surviving and dying sea trout kelts, and the results suggest the physical status of kelts prior to entering the marine environment may affect their behaviour and survival chances at sea.

\section{Acknowledgements}

The funding for this project was received through the European Regional Development Fund (the Interreg IVa "MarGen"- project, 20200411) and the Danish rod and net fish license funds. 
Aarestrup, K., Baktoft, H., Thorstad, E., Svendsen, J., Höjesjö, J. and Koed, A. 2015. Survival and progression rates of anadromous brown trout kelts Salmo trutta during downstream migration in freshwater and at sea. Marine Ecology Progress Series, 535: 185-195 of anadromous brown trout Salmo trutta during outward migration through a complex coastal habitat. Marine Ecology Progress Series, 541: 151-163.

Bendall, B., Moore A., Quayle, V. 2005. The post-spawning movements of migratory brown trout Salmo trutta L.. Journal of Fish Biology, 67: 809-822

Birnie-Gauvin, K., Flavio, H., Kristensen, M.L., Walton, S., Cooke, S.J., Willmore, W.G., Koed, A., Aarestrup, K. 2019. Cortisol predicts migration timing and success in both Atlantic salmon and sea trout kelts. Scientific Reports, 9(1):2422

Bordeleau, X., Davidsen, J. G., Eldøy, S. H., Sjursen, A. D., Whoriskey, F. G., Crossin, G. T. 2018. Nutritional correlates of spatiotemporal variations in the marine habitat use of brown trout (Salmo trutta) veteran migrants. Canadian Journal of Fisheries and Aquatic Sciences, 999: 1-11.

Brooks, M.E., Kristensen, K., van Benthem, K.J., Magnusson, A., Berg, C.W., Nielsen, A., Skaug, H.J., Maechler, M., Bolker, B.M. 2017. glmmTMB Balances Speed and Flexibility Among Packages for Zeroinflated Generalized Linear Mixed Modeling. The R Journal 9:378-400. 
Drenner, S. M., Clark, T. D., Whitney, C. K., Martins, E. G., Cooke, S. J. and Hinch, S. G. 2012. A Synthesis of Tagging Studies Examining the Behaviour and Survival of Anadromous Salmonids in Marine Environments. Plos One 7 (3): e31311

Eldøy, S. H., Davidsen, J. G., Thorstad, E.B., Whoriskey, F., Aarestrup, K., Næsje, T.F., Rønning, L., et al. 2015. Marine migration and habitat use of anadromous brown trout (Salmo trutta). Canadian Journal of Fisheries and Aquatic Sciences, 72: 1366-1378.

Eldøy S.H., Davidsen, J.G., Thorstad, E.B., Whoriskey, F.G., Aarestrup, K., Naesje, T.F., Rønning, L., et al. 2017. Marine depth use of sea trout Salmo trutta in fjord areas of central Norway. Journal of Fish Biology, 91: 1268-1288.

Halttunen, E., Jensen, J.L.A., Næsje, T.F., Davidsen, J.G., Thorstad, E.B., Chittenden, C.M., Hamel, S., et al. 2013. State-dependent migratory timing of postspawned Atlantic salmon (Salmo salar). Canadian Journal of Fisheries and Aquatic Sciences, 70: 1063-1071.

Hendry, A. P., Bohlin, T., Jonsson, Bror. Berg, O. K. 2004. To sea or not to sea. Anadromy versus nonanadromy in Salmonids. In Evolution illuminated: salmon and their relatives. Edited by A.P. Hendry and S.C. Stearns. Oxford University Press, New York, 92-125.

ICES. 2013. Report of the Workshop on Sea Trout (WKTRUTTA), 12-14 November 2013, ICES Headquarters, Copenhagen, Denmark ICES CM 2013/SSGEF:15.

Jensen, A.J., Finstad, B., Fiske, P., Hvidsten, N.A., Rikardsen, A.H., Saksgård, L. 2012. Timing of smolt migration in sympatric populations of Atlantic salmon (Salmo salar), brown trout (Salmo trutta), and Arctic char (Salvelinus alpinus). Canadian Journal of Fisheries and Aquatic Sciences, 69(4), 711-723. 
Jensen, J.L.A., Rikardsen, A.H., Thorstad, E.B., Suhr, A.H., Davidsen, J.G., Primicerio, R. 2014. Water temperatures influence the marine area use of Salvelinus alpinus and Salmo trutta. Journal of Fish Biology, 84: 1640-1653.

Jepsen, N., Flávio, H., Koed, A. 2018. The impact of Cormorant predation on Atlantic salmon and Sea trout smolt survival. Fisheries Management and Ecology.

Klemetsen, A., Amundsen, P.-A., Dempson, J.B., Jonsson, N., O'Connell, M.F. and Mortensen, E. 2003. Atlantic salmon Salmo salar L., brown trout Salmo trutta L. and Arctic charr Salvelinusalpinus (L.): a review of aspects of their life histories. Ecology of Freshwater Fish, 12: 1-59.

Kristensen, M.L., Birnie-Gauvin, K., Aarestrup, K. 2018a. Routes and survival of anadromous brown trout Salmo trutta L. post-smolts during early marine migration through a Danish fjord system. Estuarine, Coastal and Shelf Science 209: 102-109.

Kristensen, M.L., Righton, D., Del Villar-Guerra, D., Baktoft, H., Aarestrup, K. 2018b. Temperature and depth preferences of adult sea trout Salmo trutta I. during the marine migration phase. Marine Ecology Progress Series, 599: 209-224.

Kristensen, M.L., Birnie-Gauvin, K., Aarestrup, K. 2019. Behaviour of veteran sea trout Salmo trutta in a dangerous fjord system. Marine Ecology Progress Series, 616: 141-153.

L'abée-Lund, J.H. 1989. Significance of mature male parr in a small population of Atlantic salmon (Salmo salar). Canadian Journal of Fisheries and Aquatic Sciences, 46: 928-931.

Larsen, F., Krog, C., Klaustrup, M., Buchmann, K. 2015. Kortlægning af sælskader i dansk fiskeri. Report no. 299-2015 from the Technical University of Denmark, Institute for Aquatic Ressources.

McConnell, B.J., Fedak, M.A., Lovell, P., Hammond, P.S. 1999. Movements and foraging areas of grey seals in the North Sea. Journal of Applied Ecology, 36: 573-590. 
Nielsen, J., Koed, A. 2016. Fiskeribiologisk vurdering af effekterne på ørredbestandene og havørredfiskeriet ved en forventet vandløbsindsats og etablering af vådområder. Report no. 310-2016 from the Technical University of Denmark, Institute for Aquatic Resources.

Philipp, D.P., Cooke, S.J., Claussen, J.E., Koppelman, J.B., Suski, C.D., Burkett, D.P. 2009. Selection for Vulnerability to Angling in Largemouth Bass. Transactions of the American Fisheries Society, 138:1, 189199.

Rasmussen, B. 1995. Stratification and wind mixing in the Southern Kattegat. Ophelia, 42: 319-334.

Recchia, C.A., Read, A.J. 1989. Stomach contents of harbour porpoises, Phocoena phocoena (L.), from the Bay of Fundy. Canadian Journal of Zoology, 67: 2140-2146.

Reddin, D.G., Downton, P., Fleming, I.A., Hansen, L.P. and Mahon, A. 2011. Behavioural ecology at sea of Atlantic salmon (Salmo salar L.) kelts from a Newfoundland (Canada) river. Fisheries Oceanography, 20: 174-191.

Righton, D., Westerberg, H., Feunteun, E., Økland, F., Gargan, P., Amilhat, E., Metcalfe, J., et al. 2016. Empirical observations of the spawning migration of European eels: The long and dangerous road to the Sargasso Sea. Science Advances, 2(10), e1501694.

Rikardsen, A., Diserud, O.H., Elliott, J.M., Dempson, J.B., Sturlaugsson, J., Jensen, A.J. 2007. The marine temperature and depth preferences of Arctic charr (Salvelinus alpinus) and sea trout (Salmo trutta), as recorded by data storage tags. Fisheries Oceanography, 16:436-447.

Thorstad, E. B., Whoriskey, F., Uglem, I., Moore, A., Rikardsen, A. H., Finstad, B. 2012. A critical life stage of the Atlantic salmon Salmo salar: behaviour and survival during the smolt and initial post-smolt migration. Journal of Fish Biology, 81: 500-542. 
529 Thorstad, E.B., Økland, F., Westerberg, H., Aarestrup, K., Metcalfe, J.D. 2013. Evaluation of surgical

530 implantation of electronic tags in European eel and effects of different suture materials. Marine and

531 Freshwater Research, 64: 324-331.

532 Thorstad, E.B., Todd, C.D., Uglem, I., Bjørn, P.A., Gargan, P.G., Vollset, K.W., Halttunen, E., et al. 2016.

533 Marine life of the sea trout. Marine Biology, (2016) 163:47

534 Tollit, D.J., Black, A.D., Thompson, P.M., Mackay, A., Corpe, H.M., Wilson, B., Parijs, S.M.V., et al. 1998.

535 Variations in harbour seal Phoca vitulina diet and dive-depths in relation to foraging habitat. Journal of

536 Zoology, 224: 209-222.

537 Uusi-Heikillä, S., Wolter, C., Klefoth, T., Arlinghous, R. 2008. A behavioral perspective on fishing-induced

538 evolution. Trends in Ecology \& Evolution, 23: 419-421.

539 Walker, R.V., Myers, K.W., Davis, N.D., Aydin, K.Y., Friedland, K.D., Carlson, H.R., Boehlert, G.W., et al. 2000

540 Diurnal variation in thermal environment experienced by salmonids in the North Pacific as indicated by data

541 storage tags. Fisheries Oceanography, 9:2: 171-186.

542 Zuur, A.F., leno, E.N., Walker, N.J., Saveliev, A.A., Smith, G.M. 2009. Mixed Effects Models and Extensions in

543 Ecology with R. Springer 2009. 